\title{
FREQUENCY OF CORONARY ARTERY DISEASE USING CALCIUM SCORING BY 640 SLICE CT
}

\author{
Muhammad Umer ${ }^{1}$, Arshia Qamar ${ }^{1}$, Narmeen Shehzadi ${ }^{1}$, Muhammad Umair Aslam ${ }^{1}$, Sana Noor ${ }^{1}$, \\ Dr. Sarah Maryam¹, Dr Tahir Naveed ${ }^{2}$ \\ ${ }^{1}$ University Institute of Radiological Sciences and Medical Imaging Technologies, \\ Faculty of Allied Health Sciences, University of Lahore, Lahore, Pakistan \\ ${ }^{2}$ Punjab Institute of Cardiology, Lahore, Pakistan
}

\begin{abstract}
:
Coronary artery disease is the narrowing of coronary arteries which is usually caused by the atherosclerosis that leads to restriction of blood flow to the heart muscles. Atherosclerosis is a buildup of plaque or deposition of fats on the inner walls of arteries and is calculated by calcium scoring. Calcium scoring is a test to assess the presence and degree of plaque in the coronary arteries. Objective: To find the frequency of coronary artery disease using calcium scoring by 640 slice CT. Methods: A descriptive study was conducted at Punjab Institute of Cardiology, Lahore. 155 participants including 117 (75.5\%) males and 38 (24.5\%) females were selected through convenient sampling technique. SPSS version 21.0 was used for data analysis. Results: Analysis of data showed that out of 155 patients, 54 (34\%) patients had no lesion and $101(65.2 \%)$ had CAD. Only 2 patients had 5 lesions. Out of 117 males, 38 had no plaque and 40 males had moderate plaque in coronary arteries. Out of 38 females, 16 female patients had no plaque, 5 female patients had moderate plaque. $99(63.9 \%)$ patients were non-smokers, out of them, 46 patients had no plaque and 17 patients had moderate plaque. $56(36.1 \%)$ patients were smokers, out of these 8 had no plaque and 28 patients had moderate plaque. In total $103(66.5 \%)$ patients who were hypertensive, 28 patients had no plaque, 36 had moderate plaque. Out of $52(33.5 \%)$ patients who were without hypertension, 26 patients had no plaque, 36 patients had moderate plaque. Out of 155, $94(60.6 \%)$ patients had diabetes, out of these 27 patients had no plaque, 32 patients had moderate plaque. Of 61 (39.4\%) patients with diabetes, 27 had no plaque, 13 were with moderate plaque. 52 patients who were between the age of 26-35 years, 18 patients had no plaque, 14 patients had moderate plaque and of 8 patients between the age of 66-75 years, 3 had moderate plaque. Conclusions: In our sample the ratio of males was greater than females. In males, moderate plaques are most common and most of the females are those with no plaque. $54 \%$ patients have no plaque and only 3 patients have minimal plaque. Smokers were least affected. It is concluded that hypertension affects the population more than any other risk factor. From our study it is also concluded that the people within the age range of 26 to 35 years are most likely to develop CAD
\end{abstract}

Key words: Computed Tomography, Calcium Scoring, Coronary Artery Disease

DOI: $10.7176 / \mathrm{JHMN} / 71-13$

Publication date: February $29^{\text {th }} 2020$

\section{Introduction:}

Computed tomography (CT) is a non-invasive tool for the detection and quantification of coronary artery calcium (CAC), a marker for atherosclerosis. The presence and extent of CAC correlates with the overall magnitude of coronary atherosclerotic plaque burden and with the development of subsequent coronary events. ${ }^{1} \mathrm{CAC}$ is defined as a hyper-attenuating lesion $>130$ Hounsfield units with an area of 3 pixels. ${ }^{2}$ The coronary artery calcium score (CACS) severity, defined by non-contrast cardiac computed tomography, is known to predict subsequent patient outcome. ${ }^{3}$ Coronary artery calcium score (CS) has been demonstrated to have an excellent prognostic value in asymptomatic individuals. A very low rate of cardiac death and myocardial infarction $(0.4 \%)$ over 3 to 5 years has been reported for individuals without detectable calcium. ${ }^{4}$ Coronary artery calcium (CAC), detected and quantified with cardiac computed tomography, represents a reliable linear anatomic estimate of total plaque burden and is represented clinically as a "calcium score." Coronary arterial calcification is part of the development of atherosclerosis, occurs exclusively in atherosclerotic arteries, it is not present in the normal vessel wall. Coronary artery calcification occurs in small amounts in the early lesions of atherosclerosis that appear in the second and third decades of life, but it is found frequently in advanced lesions and in old age. There is a positive correlation between site and the amount of CAC and the amount of coronary luminal narrowing at the same anatomic site, the relation is around and has large confidence limits. ${ }^{6}$ An attenuation threshold of 130 Hounsfield units (HU) and a 
minimum of 3 contiguous pixels were utilized for identification of a calcific lesion. Each focus exceeding the lowest criteria was scored using the algorithm experienced by Agatston et al. calculated by multiplying the lesion area by a density factor acquired from the maximal $\mathrm{HU}$ within this area. The density factor was allocated in the following manner: 1 for lesions with highest attenuation of 130 to $199 \mathrm{HU}, 2$ for lesions with highest attenuation of 200 to $299 \mathrm{HU}, 3$ for lesions with highest attenuation of 300 to $399 \mathrm{HU}$, and 4 for lesions with highest attenuation $400 \mathrm{HU}$. The total CAC score was determined by summing individual lesion scores from each of anatomical sites (left main, left anterior descending, left circumflex, and right coronary arterie). ${ }^{7}$ The mean Hounsfield units for the largest calcification (density $150 \mathrm{mg} / \mathrm{cm} 3$ ) in a large region of interest was measured for $120-\mathrm{kVp}$ acquisition. ${ }^{8}$ From the primary analysis, these CCTA scores were calculated: Coronary obstruction score was obtained by counting the most significant plaque or stenosis of any segment; score 0 , all coronary segments $<25 \%$ and without any plaques; score 1 , at least 1 coronary segment with non-obstructive plaques ( $25 \%$ stenosis); score 2 , at least 1 coronary segment with mild stenosis $(25 \%$ to $49 \%)$; score 3 , at least 1 coronary segment with moderate stenosis (50\% to $74 \%$ ); and score 4 , at least 1 coronary segment with severe stenosis $(75 \%) .{ }^{9}$ If subjects were current smokers, they were considered to have a positive history of cigarette smoking. ${ }^{10}$ Other risk factors were recorded as categorical variables in all patients. Diabetes was defined as treatment with hypoglycemic agents or insulin, fasting glucose $>126 \mathrm{mg} / \mathrm{dl}$. Hypertension was defined as blood pressure $>140 / 90 \mathrm{~mm} \mathrm{Hg} .{ }^{11}$

The purpose of this study was to get prevalence of coronary artery disease using calcium scoring in the evaluation of coronary artery lesions in cardiac and non-cardiac patients for future coronary artery disease risk.

\section{Methods:}

It was a descriptive study conducted from July 2019 to October 2019. The study was performed at Punjab Institute of Cardiology, Lahore. Data was collected by using a pre-tested questionnaire with the help of convenient sampling technique. 155 participants aged between 19 and 75 years, were selected. After data collection, data were arranged in Microsoft Excel Sheet and were analysed by using Statistical Package for the Social Sciences (SPSS) software version 21.0.

Results:

A total of 155 patients were included in this research comprising 117 males $(75.5 \%)$ and 38 females $(24.5 \%)$. $101(65.2 \%)$ patients had CAD and 54(34.8\%) had no CAD. 38 male patients had no plaque in coronary arteries, 1 male patient had minimal plaque, 27 male patients had mild plaque, 40 male patients had moderate plaque and 11 male patients had severity of plaque in their coronary arteries. 16 female patients had no plaque, 2 female patients had minimal plaque, 15 female patients had mild plaque, 5 female patients had moderate plaque in coronary arteries as shown in Table 2.

FIGURE: 1

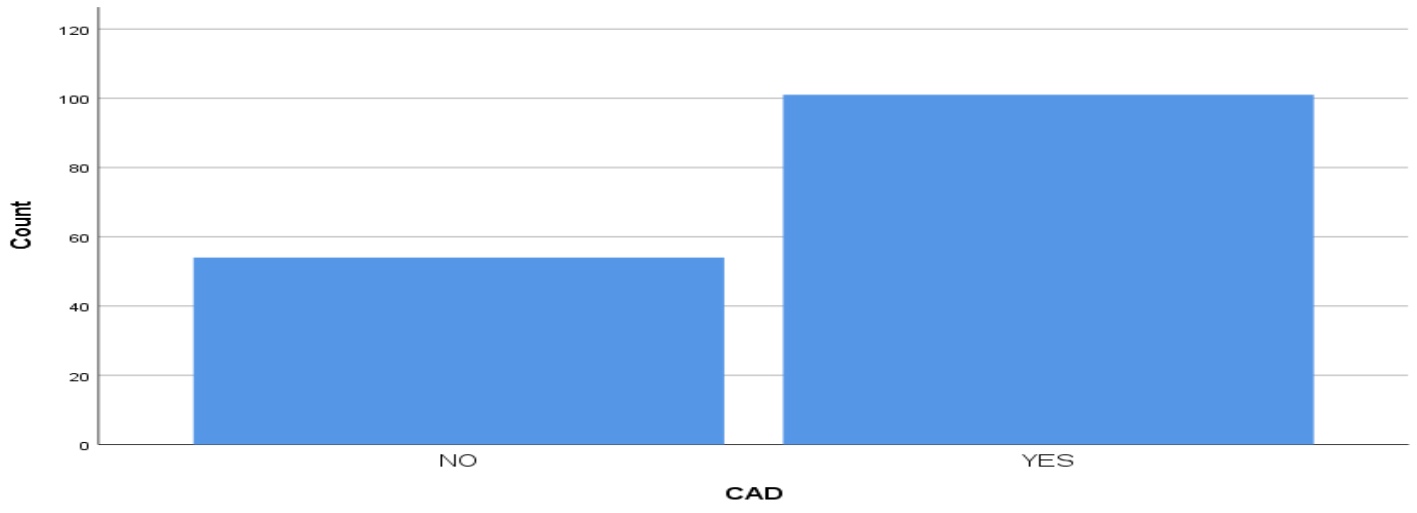


Table 1: Frequency of CAD

\begin{tabular}{cr|r}
\multicolumn{2}{c}{ CAD } & \\
& Frequency & Percent \\
\hline NO & 54 & 34.8 \\
\hline $\begin{array}{l}\text { YE } \\
\text { S }\end{array}$ & 101 & 65.2 \\
\hline $\begin{array}{l}\text { Tot } \\
\text { al }\end{array}$ & 155 & 100.0 \\
\hline
\end{tabular}

Table 2: Gender wise count

\begin{tabular}{cr|r|} 
& \multicolumn{2}{c}{ GENDER } \\
& $\begin{array}{c}\text { Frequenc } \\
\mathrm{y}\end{array}$ & Percent \\
\hline male & 117 & 75.5 \\
\hline $\begin{array}{l}\text { femal } \\
\mathrm{e}\end{array}$ & 38 & 24.5 \\
\hline Total & 155 & 100.0 \\
\hline
\end{tabular}

FIGURE: 2

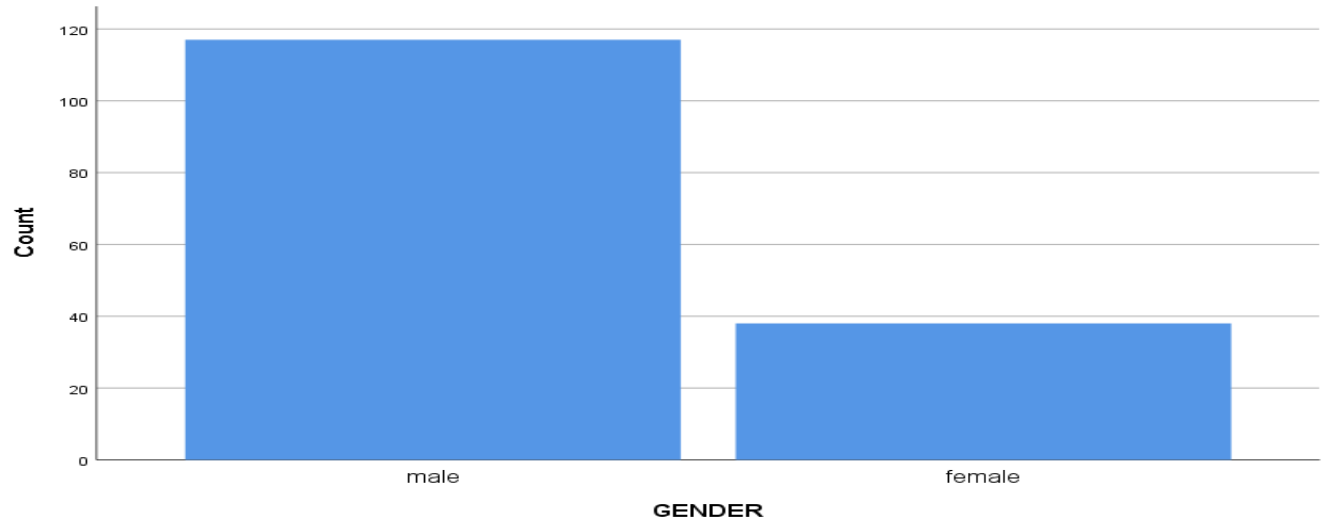

Table 2: Severity of plaque in Gender distribution

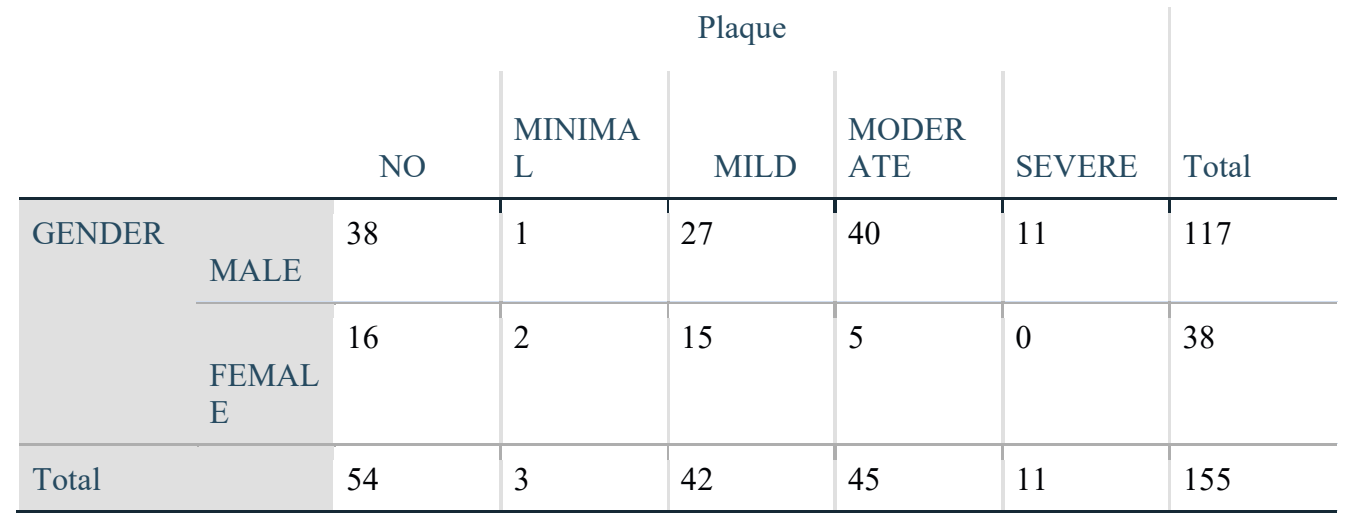


FIGURE :3

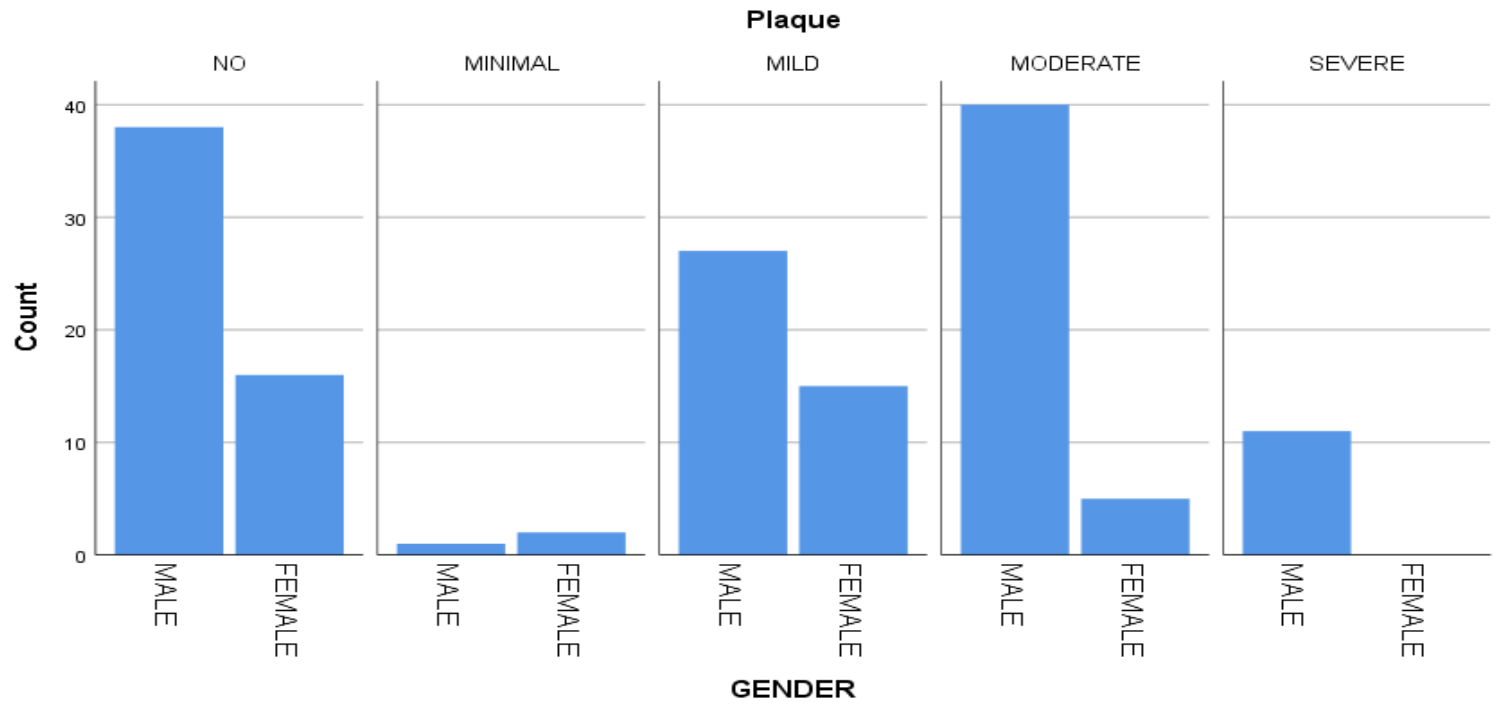

99(63.9\%) patients were non-smokers and 56(36.1\%) patients were smokers, 46 non-smokers had no calcification, 3 non-smokers had minimal calcification, 30 non-smokers had mild calcification, 17 non-smokers had moderate calcification and 3 non-smokers had severity of calcification in this study. 8 smokers had no calcification, 12 smokers had mild calcification, 28 smokers had moderate calcification and 8 smokers had severity of calcification in this study as shown in Table 3.

Table 3: Frequency of Smokers

\begin{tabular}{lr|r} 
& \multicolumn{2}{c}{ SMOKING } \\
& $\begin{array}{c}\text { Frequenc } \\
\mathrm{y}\end{array}$ & Percent \\
\hline NO & 99 & 63.9 \\
\hline $\begin{array}{l}\text { YE } \\
\text { S }\end{array}$ & 56 & 36.1 \\
\hline $\begin{array}{l}\text { Tot } \\
\text { al }\end{array}$ & 155 & 100.0 \\
\hline
\end{tabular}




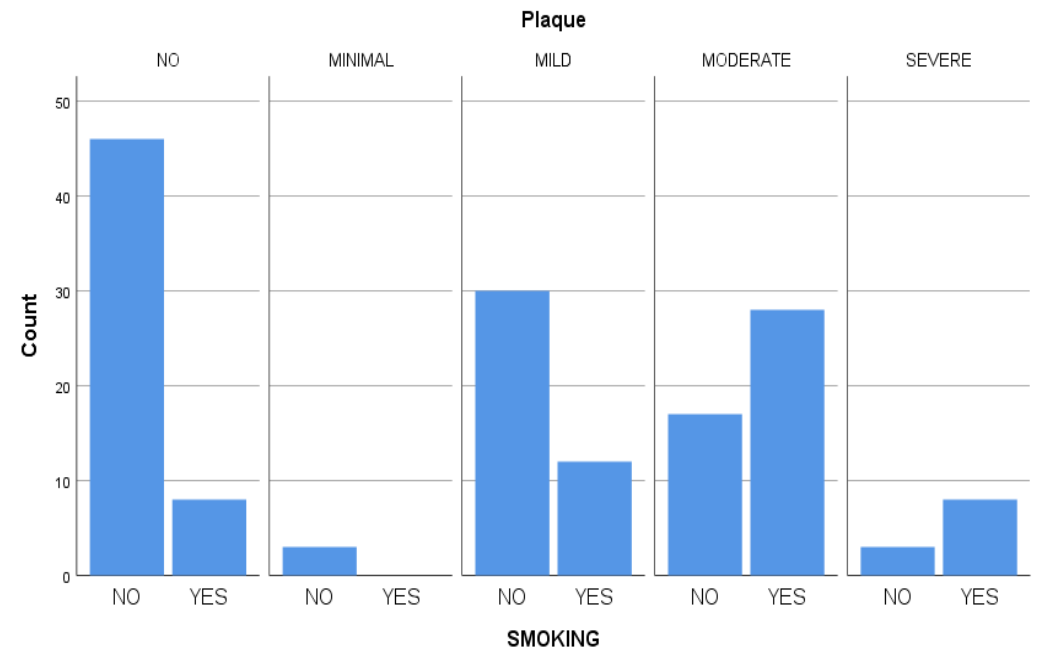

52(33.5\%) patients who did not have history of hypertension and $103(66.5 \%)$ patients with history of hypertension had calcification in coronary arteries. 28 patients with no history of hypertension had no calcification, 1 patient with no hypertension had minimal calcification, 14 patients with no hypertension had mild calcification, 26 patients with hypertension had no calcification, 2 patients with hypertension had minimal calcification, 28 patients with hypertension had mild calcification, 36 patients with hypertension had moderate calcification and 11 patients with hypertension had severe calcification in coronary arteries as shown in Table 4.

Table 4: Frequency of people with Hypertension

\begin{tabular}{cr|r} 
& \multicolumn{2}{c}{ HTN } \\
& $\begin{array}{c}\text { Frequenc } \\
\text { y }\end{array}$ & Percent \\
\hline NO & 52 & 33.5 \\
\hline $\begin{array}{l}\text { YE } \\
\text { S }\end{array}$ & 103 & 66.5 \\
\hline $\begin{array}{l}\text { Tot } \\
\text { al }\end{array}$ & 155 & 100.0 \\
\hline
\end{tabular}

\section{Graph showing frequency of people with Hypertension}

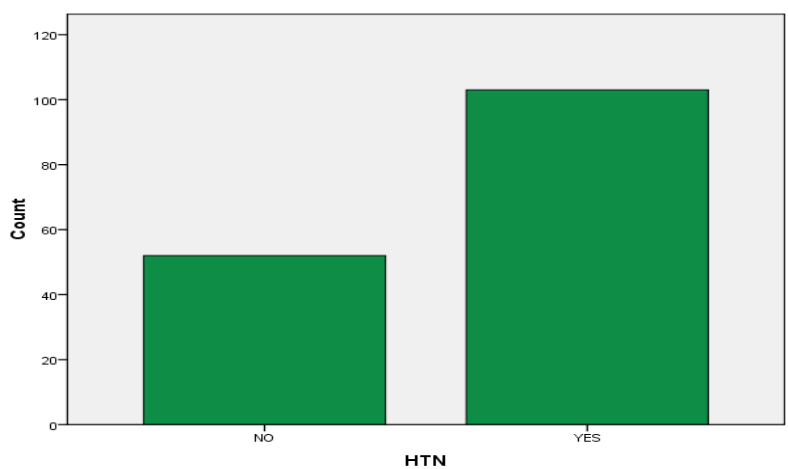


Table 4: Severity of plaque in Hypertensive people

\begin{tabular}{|c|c|c|c|c|c|c|c|}
\hline & & \multicolumn{5}{|l|}{ Plaque } & \multirow[b]{2}{*}{ Total } \\
\hline & & NO & $\begin{array}{l}\text { MINIMA } \\
\text { L }\end{array}$ & MILD & $\begin{array}{l}\text { MODER } \\
\text { ATE }\end{array}$ & SEVERE & \\
\hline \multirow[t]{2}{*}{ HTN } & NO & 28 & 1 & 14 & 9 & 0 & 52 \\
\hline & YES & 26 & 2 & 28 & 36 & 11 & 103 \\
\hline Total & & 54 & 3 & 42 & 45 & 11 & 155 \\
\hline
\end{tabular}

61(39.4\%) patients were diabetic and 94(60.6\%) patients had no diabetes. 27 non-diabetic patients had no calcification, 1 patient had minimal calcification, 27 non-diabetic patients had mild calcification, 32 patients had moderate calcification and 7 patients had severe calcification in coronary arteries. 27 diabetic patients had no calcification, 2 diabetic patients had minimal calcification, 15 patients had mild calcification, 13 patients had moderate calcification and 4 patients had severe calcification in coronary arteries as shown in Table 5.

Table 5: Frequency of diabetic people

\section{DIABETIC}

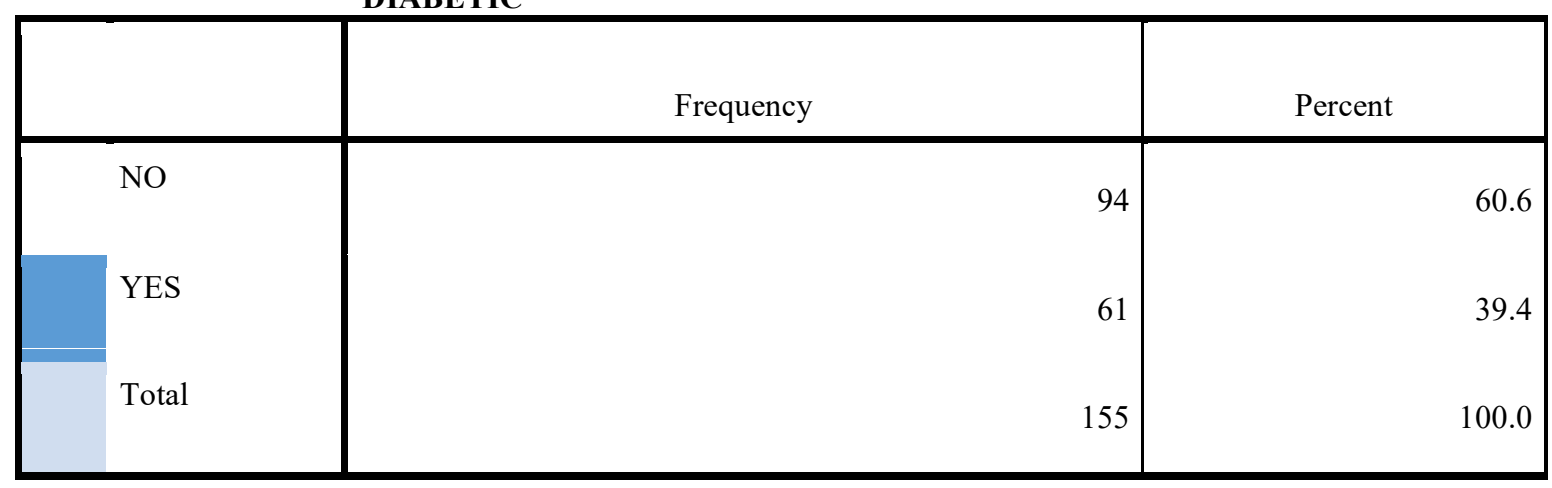

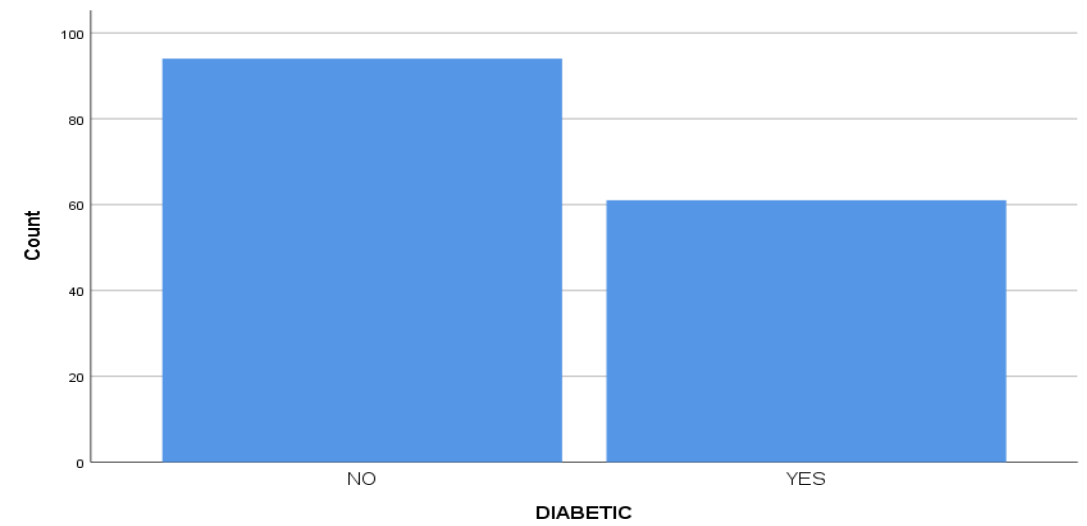


Table 5: Severity of plaque in Diabetic people

\begin{tabular}{|c|c|c|c|c|c|c|c|}
\hline & & \multicolumn{5}{|c|}{ Plaque } & \multirow[b]{2}{*}{ Total } \\
\hline & & NO & $\begin{array}{l}\text { MINI } \\
\text { MAL }\end{array}$ & MILD & $\begin{array}{l}\text { MODE } \\
\text { RATE }\end{array}$ & $\begin{array}{l}\text { SEVE } \\
\text { RE }\end{array}$ & \\
\hline \multirow{2}{*}{$\begin{array}{l}\text { DIABET } \\
\text { ES }\end{array}$} & NO & 27 & 1 & 27 & 32 & 7 & 94 \\
\hline & $\begin{array}{l}\text { YE } \\
S\end{array}$ & 27 & 2 & 15 & 13 & 4 & 61 \\
\hline Total & & 54 & 3 & 42 & 45 & 11 & 155 \\
\hline
\end{tabular}

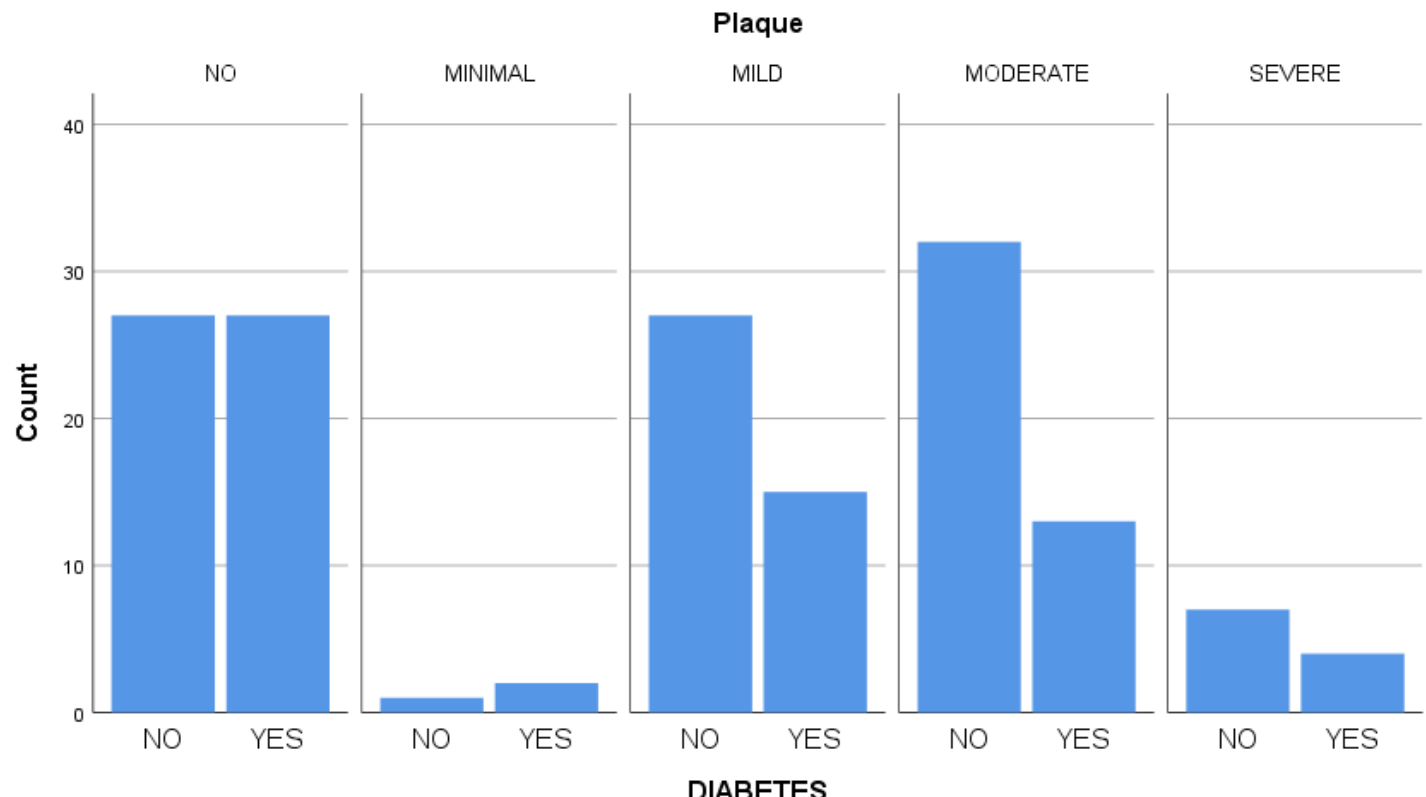

In this study, there were 54 patients who had no lesion, 37 patients who had 1 lesion, 35 patients who had 2 lesions, 18 patients who had 3 lesions, 9 patients who had 4 lesions and only 2 patients who had 5 lesions in coronary arteries as shown in Table 6 
Table 6: Frequency of total Lesions in patients

\begin{tabular}{|r|r|r|}
\hline \multicolumn{3}{|c|}{ TOTAL LESION } \\
\hline 0 & Frequency & Percent \\
\hline 1 & 54 & 34.8 \\
\hline 2 & 37 & 23.9 \\
& 35 & 22.6 \\
3 & 18 & 11.6 \\
4 & 9 & 5.8 \\
& & \\
& & \\
5 & 155 & 100.0 \\
\hline
\end{tabular}

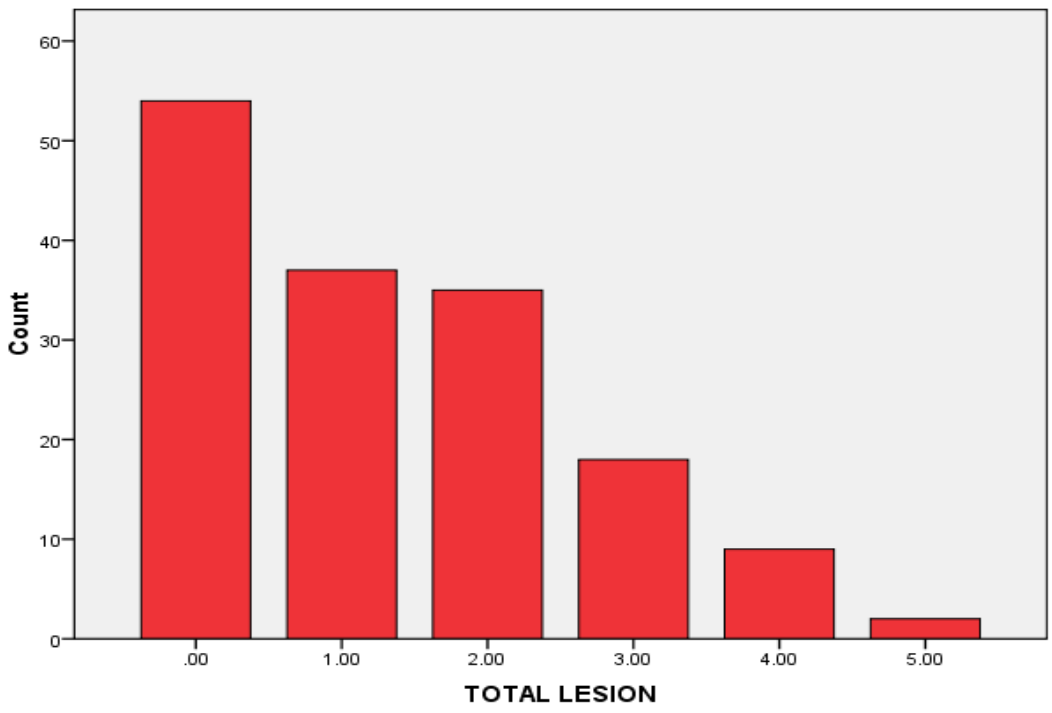

There were 12 patients between age 15-25, 52 patients between 26-35 years, 32 patients between $36-45$ years, 37 patients between $46-55,14$ patients between $56-65$ and 8 patients between $66-75$ years of age as shown in Table 7 
Table 7: Frequency of age groups

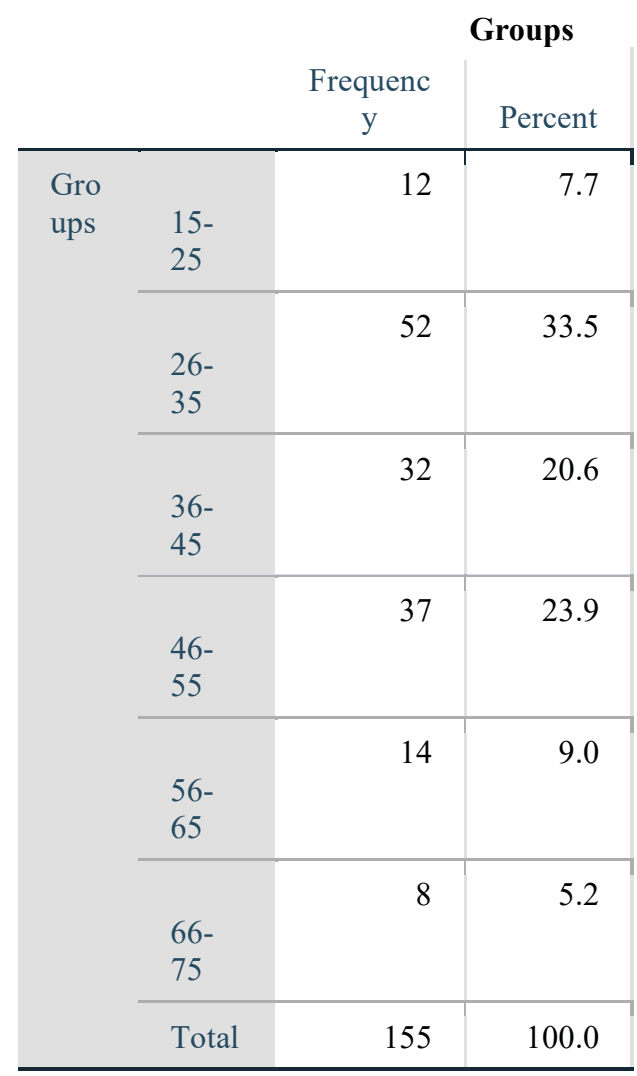

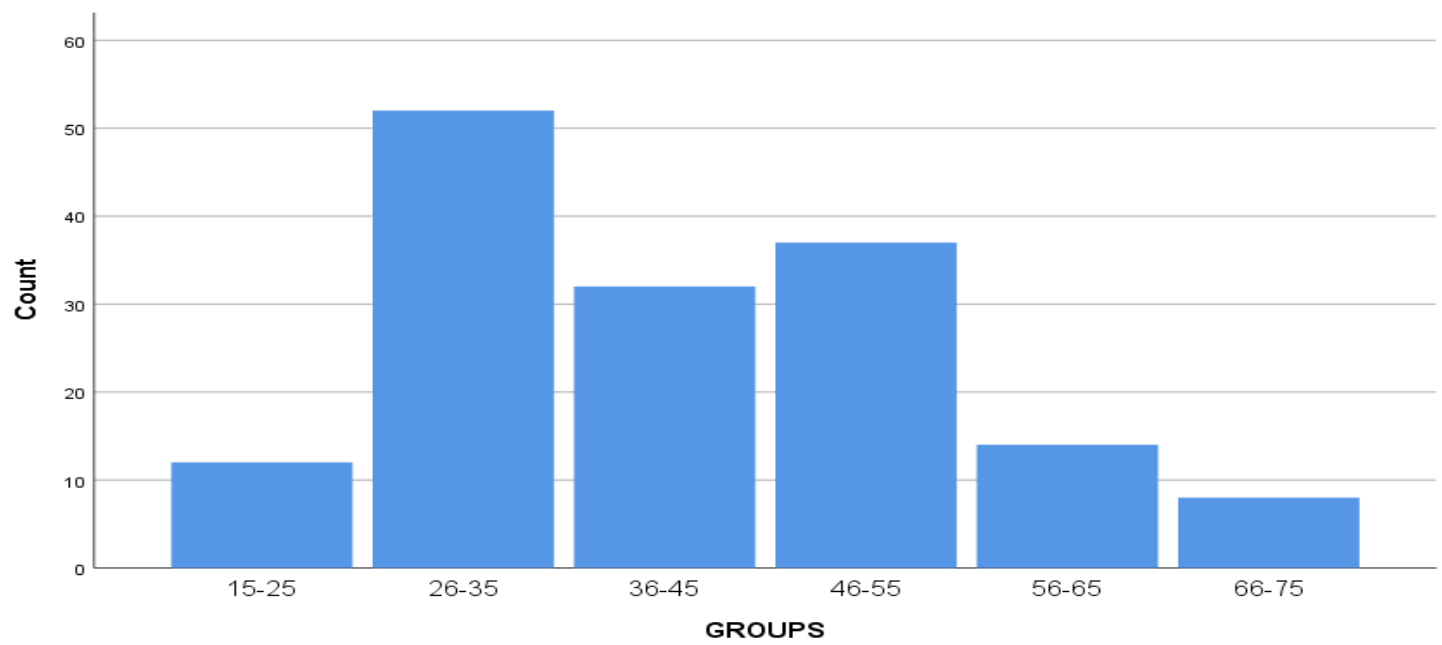


Table 8: Severity of plaque with age groups

\begin{tabular}{|c|c|c|c|c|c|c|c|}
\hline & & \multicolumn{5}{|c|}{ Plaque } & \multirow[b]{2}{*}{ Total } \\
\hline & & NO & $\begin{array}{l}\text { MINI } \\
\text { MAL }\end{array}$ & MILD & $\begin{array}{l}\text { MODE } \\
\text { RATE }\end{array}$ & $\begin{array}{c}\text { SEVE } \\
\text { RE }\end{array}$ & \\
\hline \multirow[t]{6}{*}{$\begin{array}{l}\text { GROUP } \\
\mathrm{S}\end{array}$} & $25^{15-}$ & 7 & 0 & 2 & 3 & 0 & 12 \\
\hline & $\begin{array}{l}26- \\
35\end{array}$ & 18 & 2 & 14 & 14 & 4 & 52 \\
\hline & $\begin{array}{l}36- \\
45\end{array}$ & 12 & 0 & 6 & 11 & 3 & 32 \\
\hline & $\begin{array}{l}46- \\
55\end{array}$ & 9 & 1 & 14 & 11 & 2 & 37 \\
\hline & $\begin{array}{l}56- \\
65\end{array}$ & 5 & 0 & 4 & 3 & 2 & 14 \\
\hline & $\begin{array}{l}66- \\
75\end{array}$ & 3 & 0 & 2 & 3 & 0 & 8 \\
\hline Total & & 54 & 3 & 42 & 45 & 11 & 155 \\
\hline
\end{tabular}

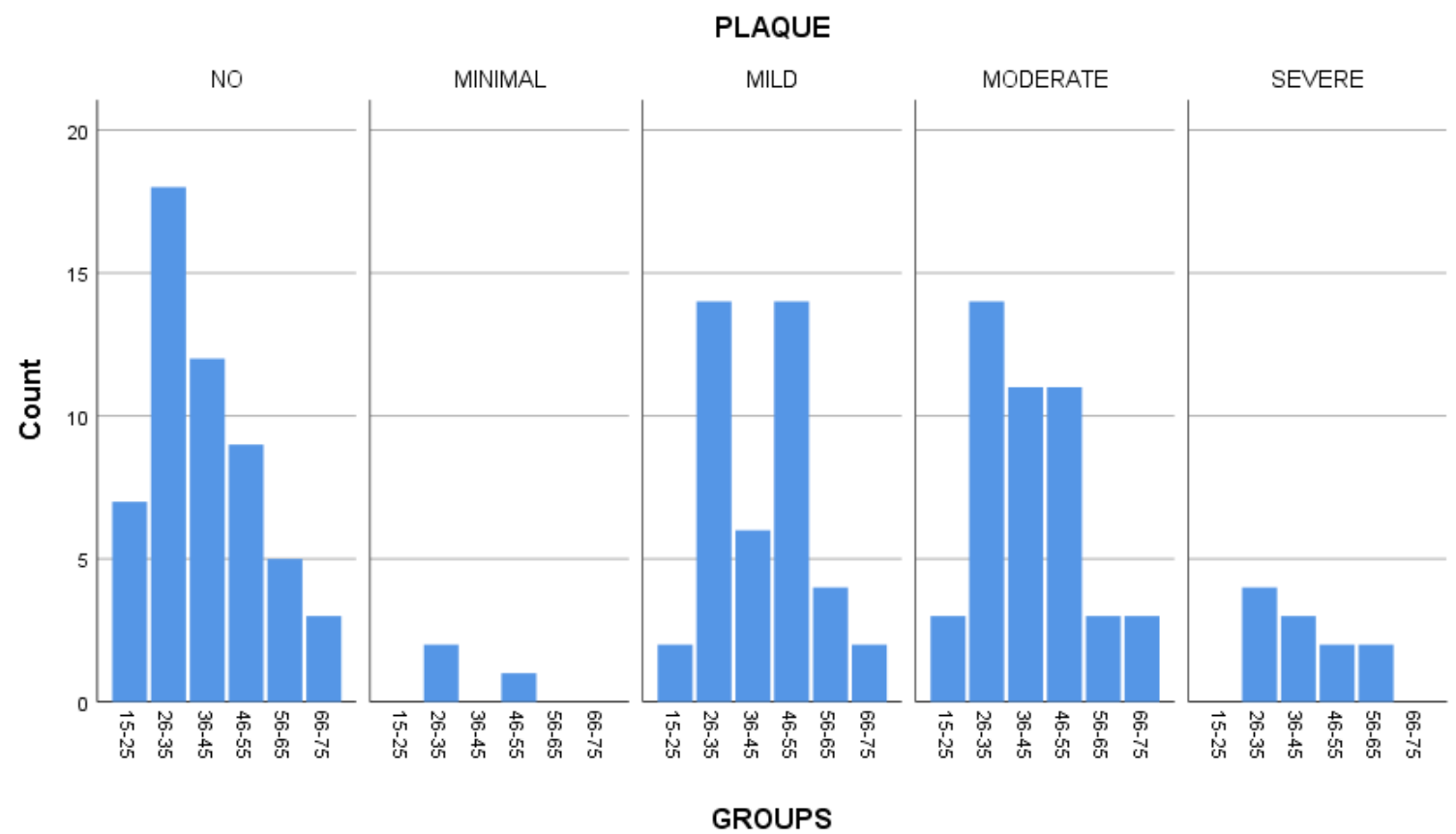


Table 9: Descriptive statistics of age

\begin{tabular}{|c|c|c|c|c|c|c|c|}
\hline \multicolumn{8}{|c|}{ Descriptive Statistics } \\
\hline & $\mathrm{N}$ & Range & $\begin{array}{c}\text { Minimu } \\
\mathrm{m}\end{array}$ & $\begin{array}{l}\text { Maximu } \\
\mathrm{m}\end{array}$ & \multicolumn{2}{|c|}{ Mean } & $\begin{array}{c}\text { Std. } \\
\text { Deviation }\end{array}$ \\
\hline & $\begin{array}{c}\text { Statisti } \\
\text { c }\end{array}$ & $\begin{array}{c}\text { Statisti } \\
\text { c }\end{array}$ & Statistic & Statistic & $\begin{array}{l}\text { Statisti } \\
\text { c }\end{array}$ & $\begin{array}{l}\text { Std. } \\
\text { Error }\end{array}$ & Statistic \\
\hline \multirow[t]{2}{*}{ Age } & 155 & 56.00 & 19.00 & 75.00 & $\begin{array}{r}41.425 \\
8\end{array}$ & 1.03536 & 12.89012 \\
\hline & 155 & & & & & & \\
\hline
\end{tabular}

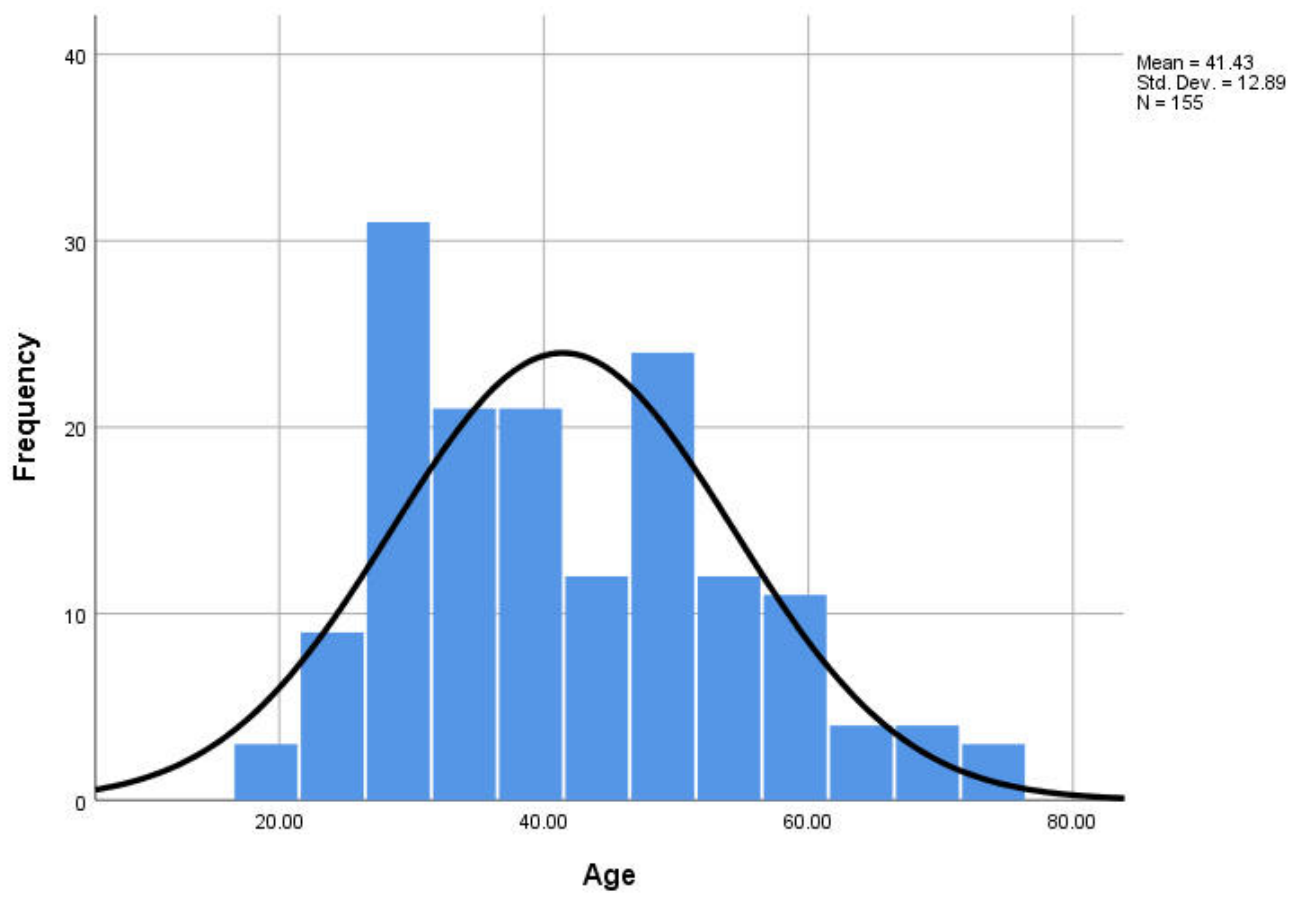

The frequency of patients with diabetes is $16(10.3 \%)$, frequency of diabetes and smoking is $5(3.2 \%)$, frequency of hypertension is 34(21.9), frequency of hypertension smoking and diabetes is $9(5.8 \%)$, frequency of hypertension and diabetes is $31(20 \%)$, frequency of hypertension and smoking is $30(19.4 \%)$, frequency of normal patients is $18(11.6 \%)$ and frequency of smokers is $12(7.7 \%)$ as shown in Table 11. 
Table 10: Frequency of Plaque

\section{PLAQUE}

\begin{tabular}{|ll|l|} 
& Frequency & Percent \\
\hline NO & 54 & 34.8 \\
\hline $\begin{array}{l}\text { MINIM } \\
\text { AL }\end{array}$ & 3 & 1.9 \\
\hline $\begin{array}{l}\text { MILD } \\
\text { MODE } \\
\text { RATE }\end{array}$ & 42 & 27.1 \\
\hline $\begin{array}{l}\text { SEVER } \\
\text { E }\end{array}$ & 11 & 29.0 \\
\hline $\begin{array}{l}\text { Total } \\
\text { Mot }\end{array}$ & 155 & 100.0 \\
\hline
\end{tabular}

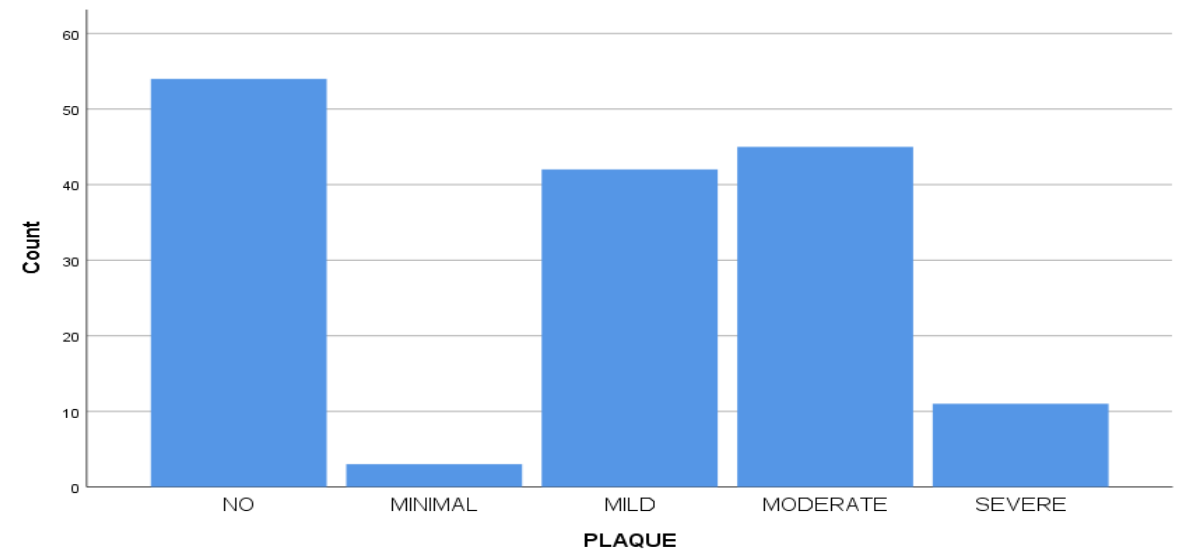


Table 11: Frequency of Factors

\begin{tabular}{|c|c|c|}
\hline & & Percent \\
\hline Diabetes & 16 & 10.3 \\
\hline Diabetes \& Smoking & 5 & 3.2 \\
\hline $\mathrm{HTN}$ & 34 & 21.9 \\
\hline $\begin{array}{l}\text { HTN, } \\
\text { Smoking \& diabetes }\end{array}$ & 9 & 5.8 \\
\hline HTN \& Diabetes & 31 & 20.0 \\
\hline HTN \& Smoking & 30 & 19.4 \\
\hline Normal & 18 & 11.6 \\
\hline Smoking & 12 & 7.7 \\
\hline Total & 155 & 100.0 \\
\hline
\end{tabular}

\section{Graph : Frequency of factors}

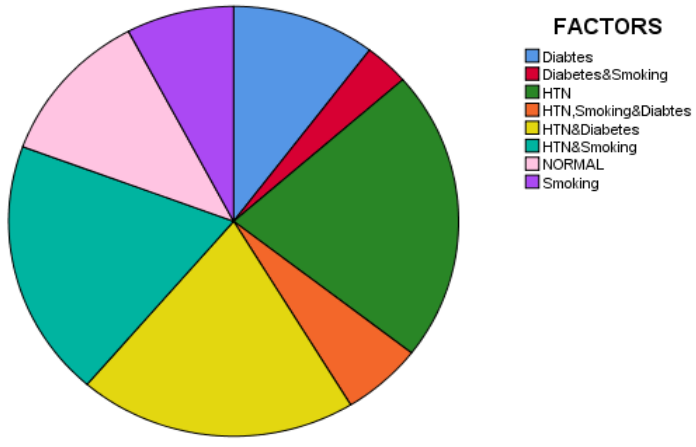

\section{DISCUSSION:}

The current study was designed to find out the frequency of CAD using calcium scoring. The severity of atherosclerotic process in arteries is predicted by presence of calcification in coronary arteries. The coronary artery calcium score predict the future coronary artery disease. The frequency of coronary artery disease is $65.2 \%$. According to the results of current study, out of 155 patients, $66.5 \%$ had hypertension, $39.4 \%$ patients were diabetic and $11.6 \%$ patients had no risk factor. Nobuo Tomizawa et al. ${ }^{12}$ conducted a study in 2015 to determine the difference of coronary artery disease (CAD) severity and a characteristics of plaque between patients with either one of hypertension, diabetes or dyslipidemia. Their sample size was large compared to ours. Out of the 1,161 patients, 38\% patients had hypertension, $7 \%$ patients were diabetic, $21 \%$ patients had dyslipidemia. In our study $34.8 \%$ patients are without any lesion and according to their study $34 \%$ patients had no disease. In our study, $11.6 \%$ patients had no risk factor associated. All of their patients had one or more risk factor. According to our study the affected males $(75.5 \%)$ were more than affected females $(24.5 \%)$. In our study, hypertension is the commonest risk factor contributing to coronary artery disease. Findings of their study supports our results that patients with HTN and diabetes were also more often males and the frequency of people with hypertension was greater than diabetic people. Another similarity in both studies is that the frequency of "no plaque" is greater in 
non-diabetic people. From both studies, it is concluded that male's patients are more affected than females and frequency of HTN is greater than any other risk factor.

They also concluded that hypertensive people had higher frequency of no plaque which is opposite to our study, according to our results, most of the hypertensive patients suffer from moderate plaque.

Another study was conducted by Nathan D. Wong et al, ${ }^{13}$ they compared the extent and prevalence of metabolic syndrome (MetS), diabetes or neither condition. They also had a large sample size as compared to us $(1,823)$. They reported that $67 \%$ of patients with diabetes had coronary calcification. In our study, $39.4 \%$ patients were diabetic. In 2015, John W. McEvoy et al, ${ }^{14}$ conducted a study. The outcome of this study suggested that $14 \%$ were smokers, former smokers were $39 \%$ and those who never smoked were $47 \%$ and in our study $63.9 \%$ participants were non-smokers which implies that in our population, smoking is not a very big contributing factor toward coronary artery disease. The results of their study showed, smokers had CAC $>100$, this supports our result as, frequency of moderate plaque $(\mathrm{CAC}>100)$ is greater in smokers in our study. From our study it is also concluded that frequency of moderate plaque is greater.

\section{Conclusion}

Estimation of coronary artery disease has been done by measuring calcification in coronary arteries by multislice CT. In our study the ratio of affected males was greater than affected females because our sample population had more males. Moderate plaques were more common in males. However, the commonest females are those with no plaque. CAD is less frequent in smokers as compared to patients with other risk factors. The ratio of diabetic patients was more than smokers but less than hypertensive people. Most of our patients with CAD were hypertensive. It is concluded that hypertension affects more than any other risk factor in our population. 34.8\% of the scanned patients had no plaque and the most common plaque was moderate (29.0\%) in type. Age range of 26 to 35 years is most prone to develop CAD. Severe plaque in coronary arteries are found in age range of 26 to 35 years. Most of the patients (both genders) have single lesion involvement in CAD. Patients having 5 lesions were least common.

\section{References:}

1. Budoff MJ, Nasir K, McClelland RL, Detrano R, Wong N, Blumenthal RS, Kondos G, Kronmal RA. Coronary calcium predicts events better with absolute calcium scores than age-sex-race/ethnicity percentiles: MESA (Multi-Ethnic Study of Atherosclerosis). Journal of the American College of Cardiology. 2009 Jan 27;53(4):345-52.

2. McEvoy JW, Blaha MJ, DeFilippis AP, Budoff MJ, Nasir K, Blumenthal RS, Jones SR. Coronary artery calcium progression: an important clinical measurement?: A review of published reports. Journal of the American College of Cardiology. 2010 Nov 9;56(20):1613-22.

3. Chang SM, Nabi F, Xu J, Peterson LE, Achari A, Pratt CM, Mahmarian JJ. The coronary artery calcium score and stress myocardial perfusion imaging provide independent and complementary prediction of cardiac risk. Journal of the American College of Cardiology. 2009 Nov 10;54(20):1872-82.

4. Henneman MM, Schuijf JD, Pundziute G, van Werkhoven JM, van der Wall EE, Jukema JW, Bax JJ. Noninvasive evaluation with multislice computed tomography in suspected acute coronary syndrome: plaque morphology on multislice computed tomography versus coronary calcium score. Journal of the American College of Cardiology. 2008 Jul 15;52(3):216-22.

5. Blaha M, Budoff MJ, Shaw LJ, Khosa F, Rumberger JA, Berman D, Callister T, Raggi P, Blumenthal RS, Nasir K. Absence of coronary artery calcification and all-cause mortality. JACC: Cardiovascular Imaging. 2009 Jun 1;2(6):692-700.

6. Greenland P, Bonow RO, Brundage BH, Budoff MJ, Eisenberg MJ, Grundy SM, Lauer MS, Post WS, Raggi P, Redberg RF, Rodgers GP. ACCF/AHA 2007 clinical expert consensus document on coronary artery calcium scoring by computed tomography in global cardiovascular risk assessment and in 
evaluation of patients with chest pain: a report of the American College of Cardiology Foundation Clinical Expert Consensus Task Force (ACCF/AHA Writing Committee to Update the 2000 Expert Consensus Document on Electron Beam Computed Tomography) developed in collaboration with the Society of Atherosclerosis Imaging and Prevention and the Society of .... Journal of the American College of Cardiology. 2007 Jan 23;49(3):378-402.

7. Budoff MJ, Hokanson JE, Nasir K, Shaw LJ, Kinney GL, Chow D, DeMoss D, Nuguri V, Nabavi V, Ratakonda R, Berman DS. Progression of coronary artery calcium predicts all-cause mortality. JACC: Cardiovascular Imaging. 2010 Dec 1;3(12):1229-36.

8. Nakazato R, Dey D, Gutstein A, Le Meunier L, Cheng VY, Pimentel R, Paz W, Hayes SW, Thomson LE, Friedman JD, Berman DS. Coronary artery calcium scoring using a reduced tube voltage and radiation dose protocol with dual-source computed tomography. Journal of cardiovascular computed tomography. 2009 Nov 1;3(6):394-400.

9. Hadamitzky M, Distler R, Meyer T, Hein F, Kastrati A, Martinoff S, Schömig A, Hausleiter J. Prognostic value of coronary computed tomographic angiography in comparison with calcium scoring and clinical risk scores. Circulation: Cardiovascular Imaging. 2011 Jan;4(1):16-23.

10. Stampfer MJ, Hu FB, Manson JE, Rimm EB, Willett WC. Primary prevention of coronary heart disease in women through diet and lifestyle. New England Journal of Medicine. 2000 Jul 6;343(1):16-22.

11. Raggi P, Gongora MC, Gopal A, Callister TQ, Budoff M, Shaw LJ. Coronary artery calcium to predict all-cause mortality in elderly men and women. Journal of the American College of Cardiology. 2008 Jul $1 ; 52(1): 17-23$.

12. Tomizawa N, Nojo T, Inoh S, Nakamura S. Difference of coronary artery disease severity, extent and plaque characteristics between patients with hypertension, diabetes mellitus or dyslipidemia. The international journal of cardiovascular imaging. 2015 Jan 1;31(1):205-12.

13. Wong ND, Sciammarella MG, Polk D, Gallagher A, Miranda-Peats L, Whitcomb B, Hachamovitch R, Friedman JD, Hayes S, Berman DS. The metabolic syndrome, diabetes, and subclinicalatherosclerosis assessed by coronary calcium. Journal of the American College of Cardiology. 2003 May 7;41(9):154753.

14. McEvoy JW, Blaha MJ, DeFilippis AP, Lima JA, Bluemke DA, Hundley WG, Min JK, Shaw LJ, Lloyd-Jones DM, Barr RG, Budoff MJ. Cigarette smoking and cardiovascular events: role of inflammation and subclinical atherosclerosis from the MultiEthnic Study of Atherosclerosis. Arteriosclerosis, thrombosis, and vascular biology. 2015 Mar;35(3):700-9. 